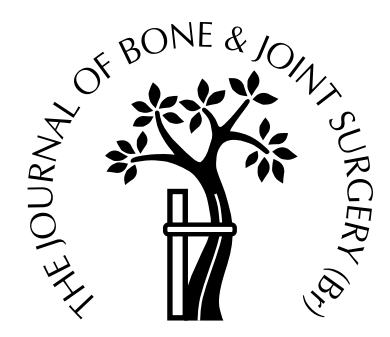

\title{
Development of the hip in diastrophic dysplasia
}

\author{
Päivi Vaara, Jari Peltonen, Mikko Poussa, Juhani Merikanto, \\ Markku Nurminen, Ilkka Kaitila, Soini Ryöppy \\ From the Hospital for Children and Adolescents, University of Helsinki and Orton \\ Orthopaedic Hospital, Invalid Foundation, Helsinki, Finland
}

W e examined 50 patients with diastrophic dysplasia both clinically and radiologically. Two legally aborted fetuses were dissected. The mean age of the patients was 16.2 years (newborn to 38) and the mean follow-up was 11.4 years (3 months to 34 years).

The fetal hips and MRI of newborn infants showed congruity and no significant joint deformity. Flexion contracture of the hip became evident later in $93 \%$ and was progressive. The radiological appearance of the proximal femoral ossific nuclei was delayed and in $17 \%$ of males and $28 \%$ of females the ossific nuclei had not appeared by the age of 12 years.

Radiological measurements differed considerably from reference values and were related to the rapid and progressive restriction of rotational movement and the increase in flexion contracture. The typical findings were flattening and inferomedial bulking of the femoral head and a double-hump deformation. The changes in the hip led to secondary osteoarthritis before early middle age. We describe the clinical and radiological measurements which define the early degeneration of the joint.

J Bone Joint Surg [Br] 1998;80-B:315-20.

Received 2 September 1997; Accepted after revision 4 November 1997

P. Vaara, MD, Senior Registrar

J. Peltonen, MD, PhD, Consultant Orthopaedic Surgeon

J. Merikanto, MD, PhD, Consultant Orthopaedic Surgeon

S. Ryöppy, MD, PhD, Consultant Orthopaedic Surgeon

Department of Paediatric Orthopaedics, Hospital for Children and Adolescents, University of Helsinki, Stenbäckinkatu 11, FIN-00290 Helsinki, Finland.

M. Poussa, MD, PhD, Consultant Orthopaedic Surgeon

Orton Orthopaedic Hospital, Invalid Foundation, Tenholantie 10, FIN00280, Helsinki, Finland.

M. Nurminen, PhD, Senior Researcher

Department of Epidemiology and Biostatistics, Finnish Institute of Occupational Health, Topeliuksenkatullaa, FIN-00250 Helsinki, Finland.

I. Kaitila, MD, PhD, Consultant Clinical Geneticist

Department of Clinical Genetics, University of Helsinki, Haartmaninkatu 2 B, FIN-00290 Helsinki, Finland.

Correspondence should be sent to Dr P. Vaara.

(C)1998 British Editorial Society of Bone and Joint Surgery 0301-620X/98/28329\$2.00

VOL. 80-B, No. 2, MARCH 1998
In Finland, a total of 183 cases of diastrophic dysplasia (DD) of the hip has been diagnosed although in other parts of the world it is a very rare condition. Autosomal recessive inheritance and the location of the gene at the distal end of chromosome $5 q$ have been verified. The DTDST gene and its mutations which are responsible for the disease have been defined $^{1,2}$ The clinical findings of short-limbed short stature, contractures of the joints, symphalangia of the fingers, hitchhiker's thumbs, deformities of the feet and often cleft palate and deformation of the ear lobes are recognisable in the newborn infant. ${ }^{3-7}$ Rigid kyphoscoliosis develops early in about $37 \%$ of these patients. ${ }^{8}$ The most disabling problems in adult patients are related to early degeneration of the hip. ${ }^{9}$

The role of recognisable predisposing conditions in the aetiology of early-onset osteoarthritis of the hip is of primary importance, ${ }^{10}$ although primary or idiopathic osteoarthritis has also been identified. ${ }^{11}$ It has been suggested that the aetiology of early osteoarthritis can be divided into three groups:

1) normal cartilage that fails when subjected to abnormal loads for long periods;

2) defective cartilage failing under normal loads; and

3 ) possible disintegration of the articular cartilage due to a defect in subchondral bone. ${ }^{12}$

Crossan and Wynne-Davies ${ }^{13}$ have considered conditions predisposing to premature osteoarthritis in two age groups, birth to 15 years and 15 to 45 years. In the younger group these include chronic juvenile arthritis, inherited skeletal dysplasias, trauma and infection, and in the older group rheumatoid arthritis, ankylosing spondylitis, Perthes' disease, acetabular dysplasia, avascular necrosis, slipped capital femoral epiphysis, congenital dislocation of the hip and primary osteoarthritis. The natural history of the hip in most of these conditions has been thoroughly investigated, with the exception of the inherited skeletal dysplasias because of their rarity and low incidence.

Our aim was to clarify the development of the hip in DD and to describe factors which influence its progressive degeneration during growth.

\section{Patients and Methods}

We evaluated 50 patients with DD from throughout Finland who had been referred to the Hospital for Children and 


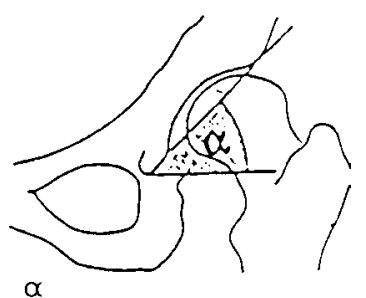

$\alpha$

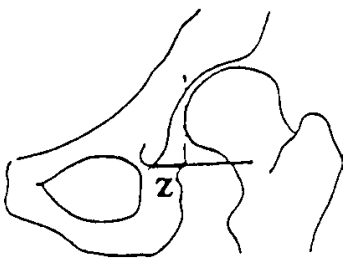

Z
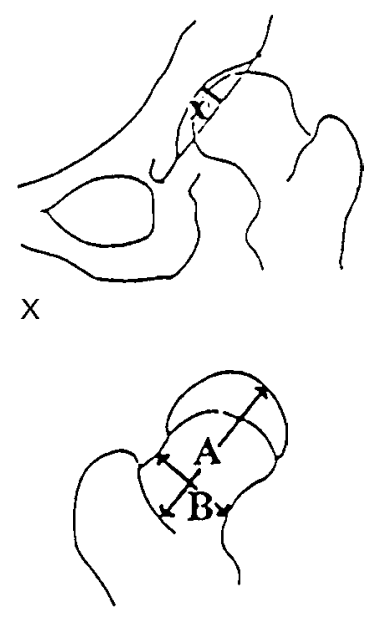

A/B
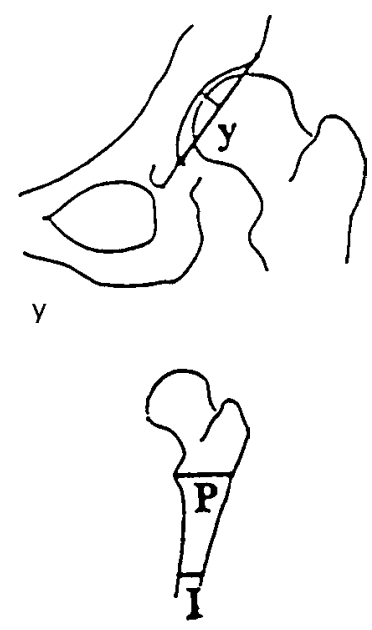

$\mathrm{l} / \mathrm{P}$

Fig. 1

Diagram showing the radiological measurements of the hip: $\alpha=$ acetabular angle, $x=$ acetabular depth, $\mathrm{y}=$ acetabular width, $\mathrm{z}=$ lateralisation of the femoral head, $\mathrm{A} / \mathrm{B}=$ femoral neck length:width ratio, and $\mathrm{I} / \mathrm{P}=$ femoral isthmus to proximal femoral width ratio.

Adolescents, Helsinki and to the Orton Orthopaedic Hospital Invalid Foundation between 1962 and 1994. The diagnosis had been confirmed in every case by a clinical geneticist at Helsinki University Central Hospital. There were 26 males and 24 females with a mean age of 16.2 years (newborn to 38). The mean follow-up was 11.4 years (3 months to 34 years). Details of the patients and of the clinical findings were obtained from hospital records. The clinical measurements included the flexion contracture ${ }^{14,15}$ and range of rotational movements of the hip. ${ }^{14-17}$

Radiological data were obtained from serial plain AP radiographs and included the acetabular angle, $\alpha,{ }_{18,19}$ the acetabular depth, $x,{ }^{19-21}$ the acetabular width, $y,{ }^{20}$ lateral subluxation (or lateralisation) of the femoral head, $z,{ }^{19}$ the femoral neck quotient or length: width ratio of the femoral neck, $\mathrm{A} / \mathrm{B}^{20,22}$ and the ratio of the femoral isthmus to the proximal femoral width, I/P (Fig. 1). We evaluated the radiological appearance and shape of the ossific nuclei for the femoral head and greater trochanter, and the congruity and configuration of the joint. Special diagnostic studies included MRI in three cases, at birth and at the age of 1.3 and 4.8 years, and the dissection of two legally aborted fetuses (at 18 and 19 weeks of gestation).

Statistical methods. The data set included radiological measurements of all 50 patients for a mean of five examinations (1 to 10). Postoperative measurements were excluded. In regression analyses, measurements which were missing were ignored in the averaging within the age groups.

The distributions of the flexion contracture and rotational movements of the hips and radiological measurements of the hips were displayed as growth curves for individual observations or as plots of mean values against age. The selected age groupings were 0 to 2,3 to 7,8 to 14 and $\geq 15$ years. For the comparison of the mean values in the four age groups, we used the age-group-specific means of the individual measurements for each patient. In addition, we used a non-parametric analysis of the measurements against age by a robust locally-weighted regression and smoothing scatterplot. ${ }^{23}$ For the occurrence of 'double-hump' deformity and the appearance of the proximal femoral epiphyses, we used 'survival functions' to show the distribution of patients with negative radiological findings. All the graphical displays and calculations were performed separately for the right and left sides using the $\mathrm{SOLO}^{24}$ and BMDP software systems.

\section{Results}

The two fetal hips (Fig. 2) and MRI of a newborn infant (Fig. 3) with severe DD showed good joint congruity with no apparent deformities. MRI at 16 months and 4.8 years showed widened femoral heads and acetabuli, with flattened proximal femoral ossific nuclei (Fig. 4). The thickness of the joint cartilage layer was decreased but joint congruity was good.

Serial radiographs showed deformity of the hip in all patients and in most of them there was progression with growth (Figs 5 to 7 ). The rate of change and the severity varied between patients (Table I, Figs 6 to 8). Clinically, the severe form produced a markedly reduced range of movement and rigid flexion contracture of the hip.

The measured variables were compared within and between the four age groups. Hip flexion contracture was noted in $93 \%$ of patients with an overall mean of $23^{\circ}$ in both right (range 0 to 80, SD 20) and left hips (range 0 to 70, sD 17) (Fig. 9a). The range of rotational movements decreased with age (Fig. 9b). Table II shows the changes in the radiological measurements. The mean acetabular angle 


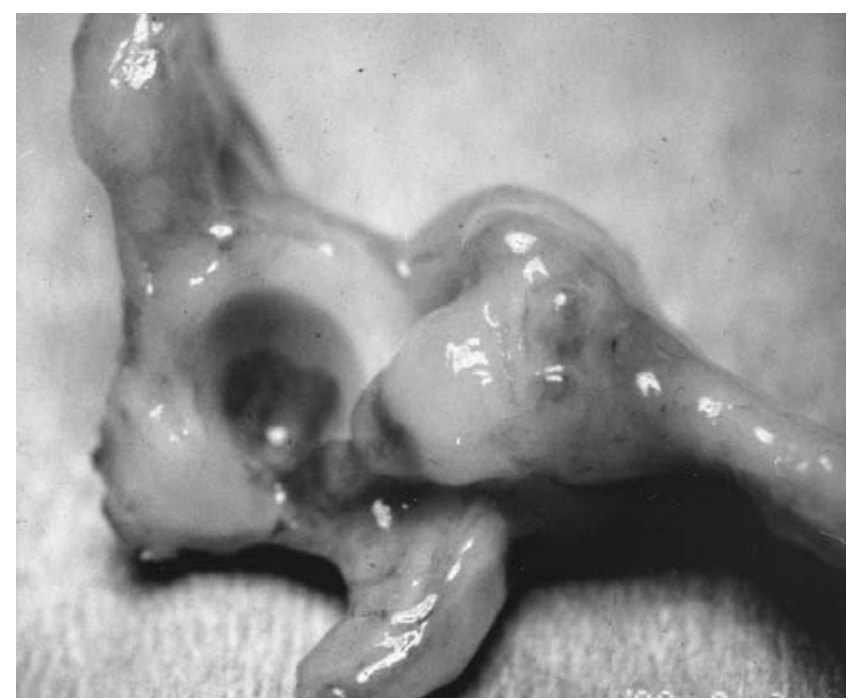

Fig. 2

Dissected hip of a legally aborted fetus at 18 weeks of gestation. The joint appears normal and congruous.

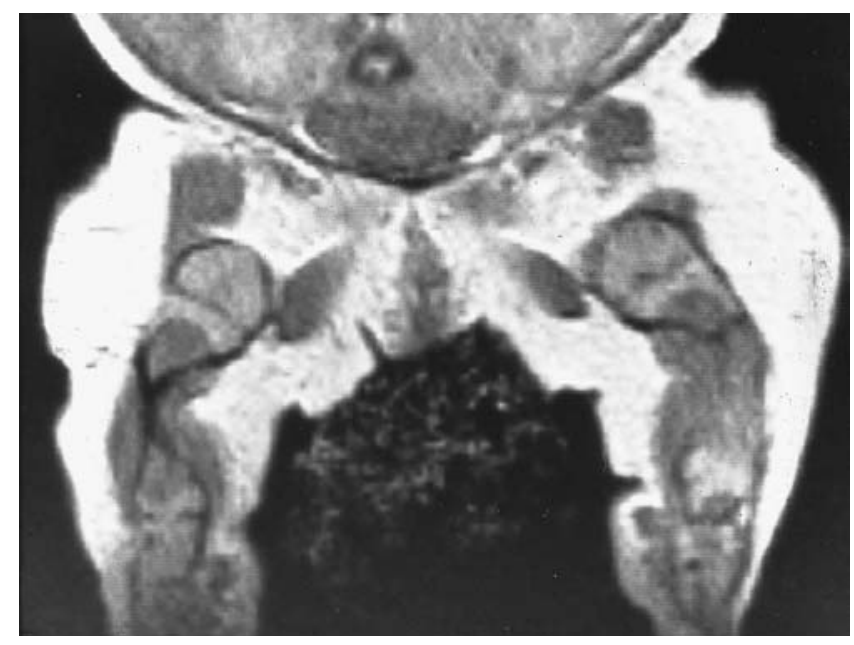

Fig. 3

MRI of the hips of a four-month-old girl. The joints are spherical with no deformity of the proximal femoral epiphyses.

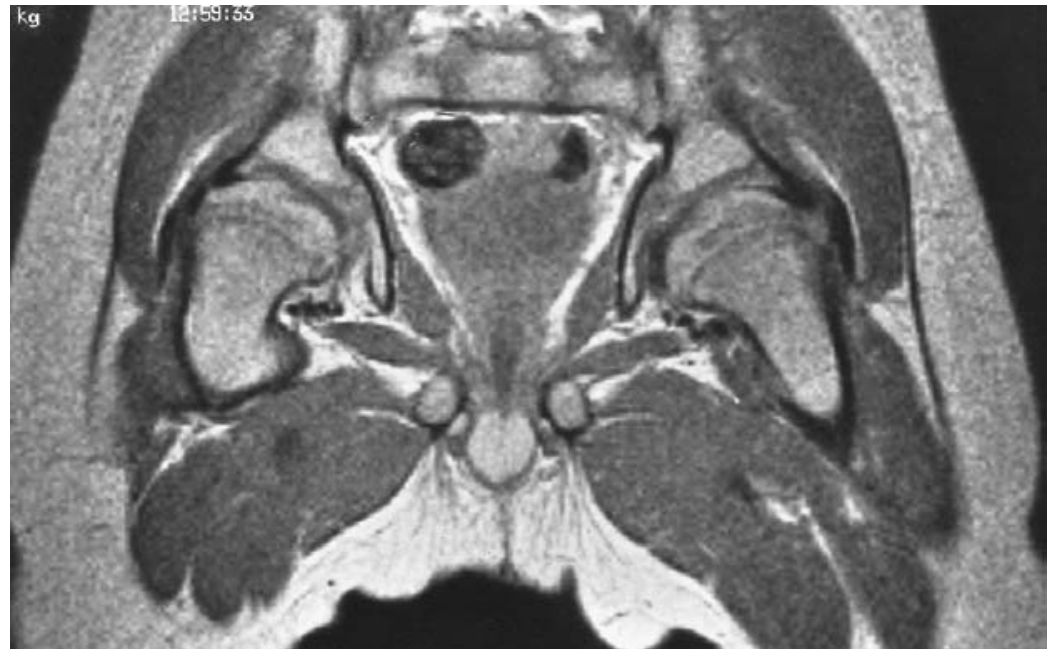

Fig. 4

MRI of the hips of a 16-month-old boy. There is flattening of the epiphyseal cartilage and a shallow acetabulum.

$(\alpha)$ was $45^{\circ}, 1.3$ times that of a normal hip ${ }^{18}$ and the mean acetabular depth (x) and width (y) were equivalent to $44 \%$ and $69 \%$, respectively of those in a normal adult hip. ${ }^{20}$ The mean lateralisation of the femoral head (z) was 13 to $14 \mathrm{~mm}$ (right hip-left hip) and the femoral neck length: width ratio $(\mathrm{A} / \mathrm{B})$ remained $<1$ in all age groups. The mean $\mathrm{A} / \mathrm{B}$ ratio was only $47 \%$ of the value of 1.82 reported for a normal adult hip. ${ }^{20}$ The ratio of the femoral diaphyseal isthmus to the proximal femoral width $(\mathrm{I} / \mathrm{P})$ indicated the short, proximally wide and diaphyseally narrow form of the femur in DD.

The appearance of the ossific nuclei of the proximal femoral epiphyses was clearly delayed. ${ }^{26}$ Capital femoral bony epiphyses were not observed until 12 years of age in $23 \%$ of the males and in $28 \%$ of the females, and at this age the ossific nucleus of the greater trochanter was not visible in $17 \%$ of males and $18 \%$ of females.
In most patients ( $73 \%$ of males, $72 \%$ of females) the shape of the joint remained nearly spherical although there was clear overgrowth of the greater trochanter beyond the femoral head. The 'double-hump' deformity developed in $27 \%$ of males and in $28 \%$ of females. In the four age groups respectively, the double hump was observed in $0 \%$, $16 \%, 23 \%$ and $27 \%$ of the males and in $0 \%, 20 \%, 28 \%$ and $28 \%$ of females.

\section{Discussion}

The orthopaedic problems in DD are severe and begin in early infancy. Kopits ${ }^{27}$ and Walker et al ${ }^{4}$ have described changes in the joints of these patients, but the manifestation of the deformities varies between patients, and there are varying degrees of difficulty as has been shown by Ryöppy et al. 


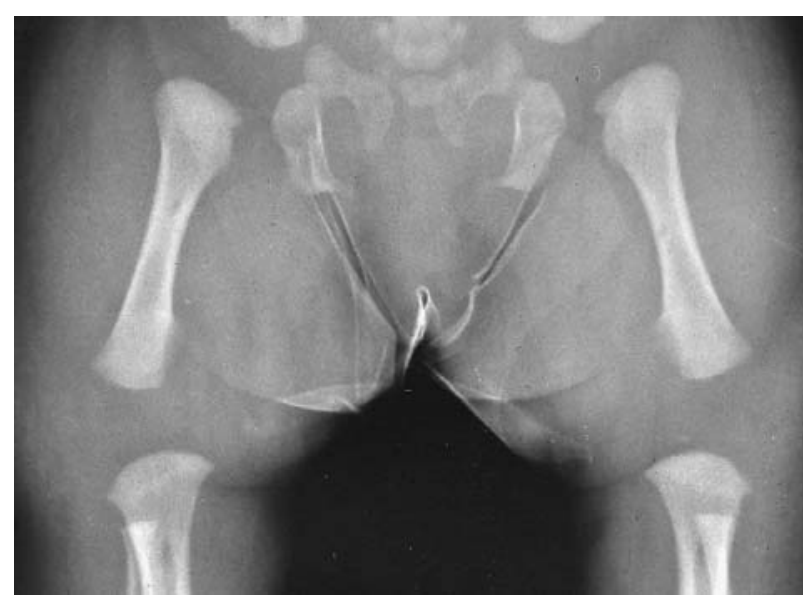

Fig. 5

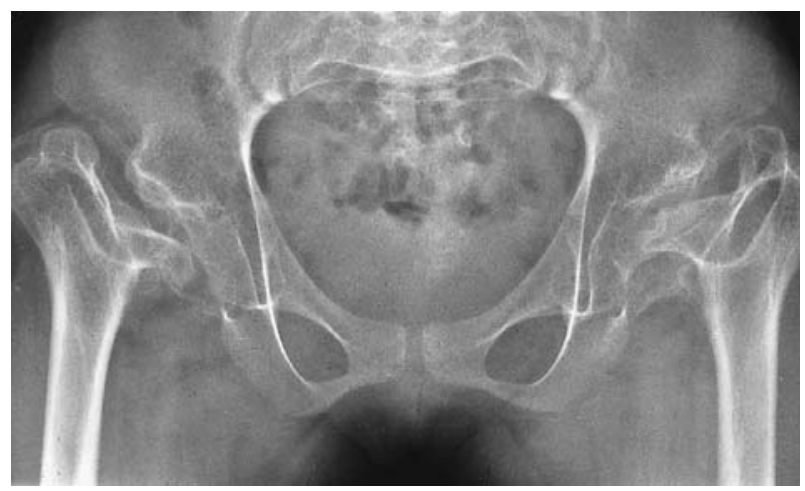

Figures 5 to 7 - AP radiographs of the hips of a female patient at the age of 0,6 and 12 years, respectively, with a severe form of progressive deformation. The pathological changes include non-appearance of the capital ossific centre, inferomedial bulking of the femoral head, a poorly developing femoral neck, a shallow acetabulum, overgrowth of the greater trochanter and a double-hump deformity of the acetabulum, worse on the left.

Fig. 7

Table I. Features of the types of deformation of the hip in DD

\begin{tabular}{|c|c|c|}
\hline Deformity & Moderate & Severe \\
\hline Femoral head & $\begin{array}{l}\text { Flattened } \\
\text { Nearly spherical }\end{array}$ & $\begin{array}{l}\text { Markedly flattened } \\
\text { Inferomedial bulking }\end{array}$ \\
\hline Femoral neck & Shortened & Remarkably short, widened \\
\hline Femoral epiphyses & $\begin{array}{l}\text { Late-appearing } \\
\text { Visible }\end{array}$ & $\begin{array}{l}\text { Non-forming or late-appearing } \\
\text { Non-visible or visible: if visible, } \\
\text { grossly deformed, fragmented }\end{array}$ \\
\hline Greater trochanter & Overgrowth & Prominent overgrowth \\
\hline Acetabulum & Shallow, even & Shallow, flat-roof-like \\
\hline Joint congruity & Satisfactory & $\begin{array}{l}\text { 'Double-hump' configuration } \\
\text { Marked loss of joint space }\end{array}$ \\
\hline
\end{tabular}

There have been no detailed studies of the development of the hip in DD, but it is known that severe and deforming osteoarthritis occurs in early middle age. ${ }^{9}$ Joint stiffness, restricted mobility and abnormal development of the proximal femoral epiphyses with early-onset degeneration and deformity have been reported for every type of inherited skeletal dysplasia, ${ }^{13}$ but the factors responsible and those which can predict deformity have not been defined. Several conditions such as avascular necrosis, congenital dislocation, acetabular dysplasia or acetabular deformity are likely to lead to early osteoarthritis. ${ }^{12}$
The microscopic changes in early-onset osteoarthritis have been discussed because injury to any one of the joint structures may lead to functional failure and to clinical arthritis. When an initial injury is not repaired and becomes chronic, the result is progressive degeneration of the joint. ${ }^{28}$

In 1994 the DTDST gene, mutations of which result in DD, was isolated and shown to code for a novel sulphate transporter protein. ${ }^{2}$ It is assumed that sulphation of the proteoglycans or other components of the cartilage matrix is defective and therefore the load-bearing ability of the articular cartilage is impaired. The pattern of the degener- 


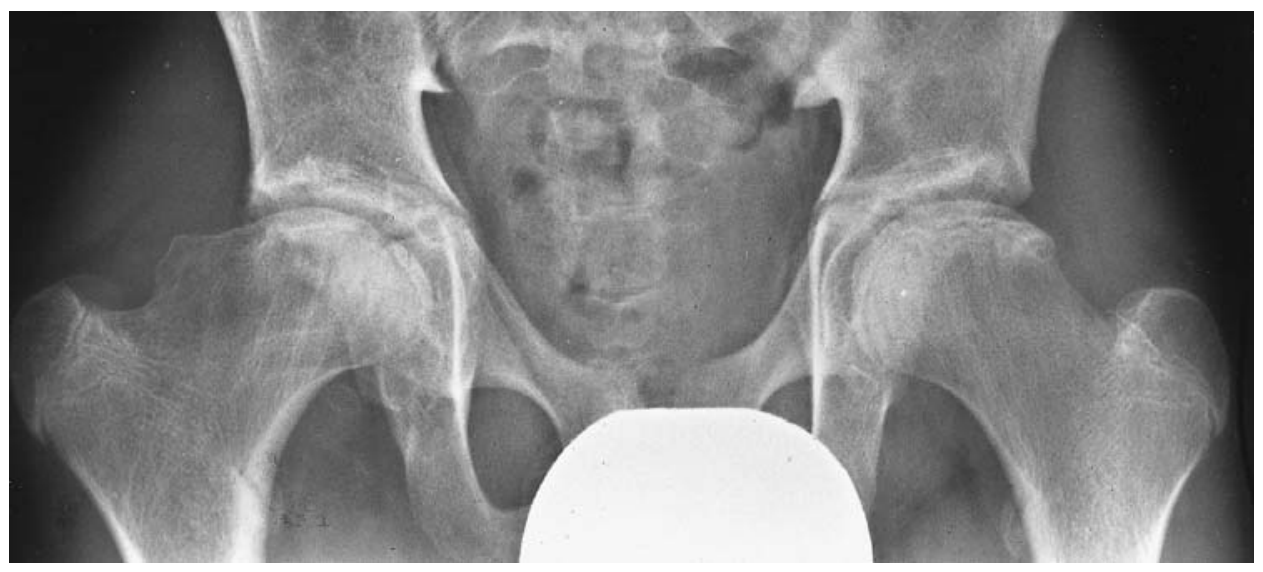

Fig. 8

AP radiograph of the hips of a 13-year-old boy with moderate deformity. The pathological changes are less severe with flattened but visible proximal femoral bony epiphyses, a well-developing femoral neck and a more spherical acetabulum.

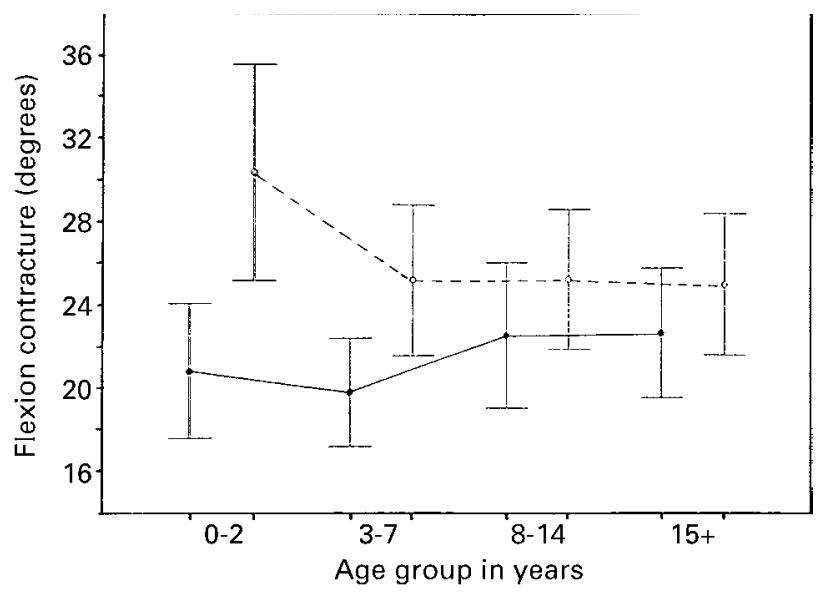

Fig. 9a

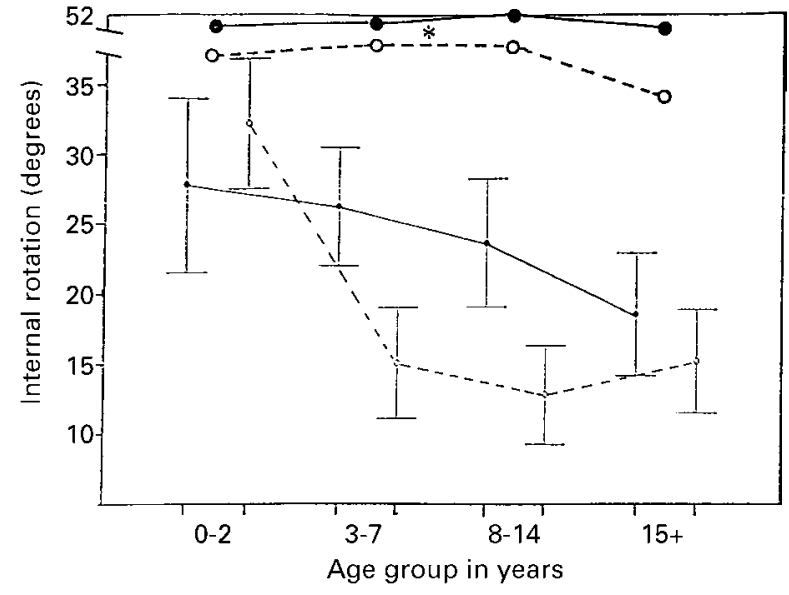

Fig. $9 \mathrm{~b}$

Changes in flexion contracture (a) and internal rotation (b) in the four age groups. The age-group-specific mean values ( \pm 1 SEM) are given separately for males (full circles with solid line) and females (open circles with dotted line). Reference values are shown above (circles larger in diameter) for males and females marked with *.

Table II. Radiological changes in the hip, separately for the right and left sides. The mean values, SD and range are shown for each measurement with values for a normal adult hip for comparison

\begin{tabular}{llll}
\hline Measurement & Right & Left & Normal adult hip \\
\hline Acetabular angle, $\alpha$, in degrees & $45 \pm 9(28$ to 66$)$ & $45 \pm 8(0$ to 65$)$ & 35 \\
Acetabular depth, $\mathrm{x}$, in $\mathrm{mm}$ & $12 \pm 9(4$ to 27$)$ & $12 \pm 8(4$ to 29$)$ & 27 \\
Acetabular width, $\mathrm{y}$, in $\mathrm{mm}$ & $54 \pm 14(17$ to 98$)$ & $55 \pm 15(18$ to 107$)$ & 80 \\
Lateralisation of femoral head, z, in mm & $13 \pm 6(4$ to 49$)$ & $14 \pm 6(4$ to 42$)$ & \\
Femoral neck length:width ratio, A/B & $0.88 \pm 0.27(0.16$ to 1.63$)$ & $0.84 \pm 0.27(0.14$ to 1.53$)$ & 1.82 \\
Femoral isthmus:proximal width ratio, I/P & $0.49 \pm 0.09(0.17$ to 0.71$)$ & $0.50 \pm 0.08(0.17$ to 0.70$)$ & \\
\hline
\end{tabular}

ative process is thus associated with normal loading forces operating on abnormal cartilage. ${ }^{12}$ It is probable that other anatomical structures containing connective tissue, such as articular capsules, ligaments and tendons, and even subchondral bone, are also affected. All such defects are likely to make loading more abnormal, causing an acceleration of the degenerative process. It is difficult to distinguish prim- ary from secondary deformities. Figure 10 illustrates our hypothesis in the form of a cascade of factors likely to cause early progressive degeneration.

The most marked change which we found was in flexion contracture. Measurement of the range of movements is commonly used, but this is an imprecise method of detecting progressive stiffness. ${ }^{16}$ We selected the most appro- 


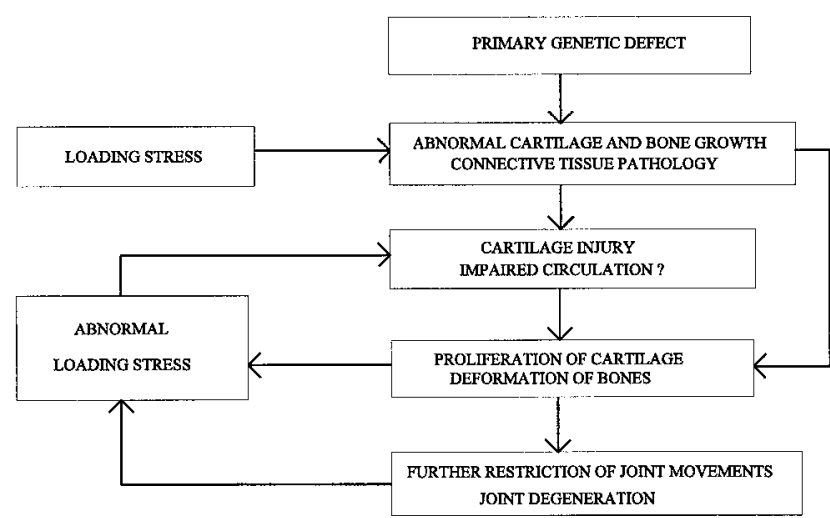

Fig. 10

Algorithm showing the cascade of factors assumed to be responsible for the early degeneration of the hip in DD.

priate of the radiological measurements as being indicative of the pathological changes. A shortened femoral neck, a wide, bulky femoral head or a totally disintegrated head, together with an overgrown greater trochanter gave severe restriction of movement, the extreme being a hinge joint. The short femoral neck and the simultaneous overgrowth of the greater trochanter are apparently due to pathological changes in the proximal femoral growth area. These changes are seen in radiographs as the non-appearance or eggshell-shape of bony ossific epiphyseal centres. The changes in the femoral head and neck, with flattening and sometimes disappearance of the bony epiphysis with coxa brevis, may be due to a defect of the circulation or disturbance of the metabolism of the articular cartilage. These pathological changes and the resulting deformation resemble other conditions causing avascular necrosis.

We were able to divide our DD patients into two categories: a moderate group and a severe group (Table I), according to the severity of the degenerative changes. In all patients the hips became deformed and early osteoarthritis seemed to develop in every case even in those showing relatively moderate changes in adolescence and early adult life.

This study has been supported by grants from the Ulla Hjelt Fund of the Foundation for Paediatric Research, the Foundation for Orthopaedic and Traumatologic Research in Finland and the Siviä Kosti Fund.

No benefits in any form have been received or will be received from a commercial party related directly or indirectly to the subject of this article.

\section{References}

1. Hästbacka J, Kaitila I, Sistonen P, de la Chapelle A. Diastrophic dysplasia gene maps to the distal long arm of chromosome 5. Proc Natl Acad Sci USA 1990;87:8056-9.

2. Hästbacka J, de la Chapelle A, Mahtani MM, et al. The diastrophic dysplasia gene encodes a novel sulfate transporter: positional cloning by fine-structure linkage disequilibrium mapping. Cell 1994;78: 1073-87.
3. Lamy M, Maroteaux P. Le nanisme diastrophique. Presse méd 1960; 68:1977-80.

4. Walker BA, Scott CI, Hall JG, et al. Diastrophic dwarfism. Medicine 1972;51:41-59.

5. Kaitila I, Marttinen E, Merikanto J, Poussa M, Ryöppy S. Clinical expression and course of diastrophic dysplasia. Am J Med Genet 1989;24:141.

6. Ryöppy S, Poussa M, Merikanto J, Marttinen E, Kaitila I. Deformities of the lower extremities in diastrophic dysplasia. Acta Orthop Scand 1990;61 [Supp]237:49-50.

7. Ryöppy S, Poussa M, Merikanto J, Marttinen E, Kaitila I. Foot deformities in diastrophic dysplasia: an analysis of 102 patients. J Bone Joint Surg [Br] 1992;74-B:441-4.

8. Poussa M, Merikanto J, Ryöppy S, Marttinen E, Kaitila I. The spine in diastrophic dysplasia. Spine 1991;16:881-7.

9. Peltonen JL, Hoikka V, Poussa M, Paavilainen T, Kaitila I. Cementless hip arthroplasty in diastrophic dysplasia. J Arthroplasty 1992;7 (suppl):369-76.

10. Halley DK, Wroblewski BM. Long-term results of low-friction arthroplasty in patients 30 years of age or younger. Clin Orthop 1986; 211:43-50.

11. Bisla RS, Inglis AE, Ranawat CS. Joint replacement surgery in patients under thirty. J Bone Joint Surg [Am] 1976;58-A:1098-104.

12. Solomon L. Patterns of osteoarthritis of the hip. J Bone Joint Surg [Br] 1976;58-B:176-83.

13. Crossan J, Wynne-Davies R. Early-onset osteoarthritis of the hip: causes, incidence and natural history. In: Reynolds D, Freeman M, eds. Osteoarthritis in the young adult hip. Edinburgh, etc: Churchill Livingstone, 1989:5-23.

14. Haas SS, Epps CH, Adams JP. Normal ranges of hip motion in the newborn. Clin Orthop 1973;91:114-8.

15. Coon V, Donato G, Houser C, Bleck EE. Normal ranges of hip motion in infants six weeks, three months and six months of age. Clin Orthop 1975; 110:25-60.

16. American Academy of Orthopaedic Surgeons. Joint motion: method of measuring and recording. Chicago, 1965.

17. Staheli LT, Corbett M, Wyss C, King H. Lower-extremity rotational problems in children. J Bone Joint Surg [Am] 1985;67-A;39-47.

18. Sharp IK. Acetabular dysplasia: the acetabular angle. J Bone Joint Surg [Br] 1961;43-B:268-72.

19. Høgh J, Macnicol MF. The Chiari pelvic osteotomy: a long-term review of clinical and radiographic results. J Bone Joint Surg $[\mathrm{Br}]$ 1987;69-B:365-73.

20. Heyman CH, Herndon CH. Legg-Perthes disease: a method for the measurement of the roentgenographic result. J Bone Joint Surg [Am] 1950;32-A:767-8.

21. Cooperman DR, Wallensten R, Stulberg SD. Acetabular dysplasia in the adult. Clin Orthop 1983;175:79-85.

22. Schiller MG, Axer A. Legg-Calvé-Perthes syndrome (L.C.P.S.): a critical analysis of roentgenographic measurements. Clin Orthop 1972;86:34-42.

23. Cleveland WS. Robust locally weighted regression and smoothing scatterblots. J Am Stat Ass 1979;74:829-36.

24. Hintze J. Copywright owner. SOLO Statistical System, Version 2.0 Graphics 8/88. Los Angeles: BMDP Statistical Software, Inc, 1988.

25. Dixon WJ. Editor. BMDP Statistical Software Manual, Vol. 2. Berkeley: University of California Press, 1990 and1992.

26. Pettersson H, Theander G. Ossification of femoral head in infancy. 1. Normal standards. Acta Radiol [Diagn] 1979;20:170.

27. Kopits SE. Orthopaedic complications of dwarfism. Clin Orthop 1976;114:153-79.

28. Bullough PG. The pathology of degenerative change in the hip. In: Reynolds D, Freeman M, eds. Osteoarthritis in the young adult hip. Edinburgh, etc: Churchill Livingstone, 1989;36-49. 